\title{
The recent trends in tuberculosis in the urban population of Western Delhi- A detailed report from a large center
}

\author{
Sankalp Yadavi,*, Gautam Rawal ${ }^{2}$ \\ ${ }^{1}$ Dept. of Medicine \& Tuberculosis, Chest Clinic Moti Nagar, North Delhi Municipal Corporation, New Delhi, ${ }^{2}$ Dept. of \\ Respiratory Intensive Care, Max Super Specialty Hospital, Saket, New Delhi, India
}

\section{*Corresponding Author:}

Email: drsankalpyadav@gmail.com

\begin{abstract}
Background: Tuberculosis is a global problem. However, the impact on the countries of Africa and Asia is really devastating. The countries like India which comes under high burden countries with TB, the prevalence of TB in the nation's capital and at a large district in the west Delhi has not been reported so far in the medical literature. The present study is a retrospective study and data will serve as a tool to formulate new or modify already existing guidelines and devise methods to control and eradicate TB from the urban population.

Materials and Methods: We conducted a retrospective descriptive study at the Chest Clinic Moti Nagar from 2010 to 2015 . The data were obtained from the quarterly reports freely available on the internet.

Results: There has been a steady rise in the diagnosis of various types of TB cases falling under DOTS and DOTS-Plus strategies of the Revised National Tuberculosis Control Programme.

Conclusions: The RNTCP is the best solution to the problem of TB. The role of well trained and dedicated staff inclined to solve the various problems associated with the TB patients is very important.
\end{abstract}

Keywords: Aerosol; Mycobacterium tuberculosis; TB; WHO.

\section{Introduction}

Tuberculosis (TB) is a significant cause of death worldwide[1-3]. The World Health Organization (WHO) declared TB as a global problem in the year 1993[4,5]. TB is an infectious disease caused by the acid-fast bacillus Mycobacterium tuberculosis and is one of the major public health problems in developing countries like India[3,4]. The transmission of TB occurs commonly by aerosols and besides, lungs, it can occur in any other part of the body[1,4]. The TB of the lung is known as pulmonary TB and that involving other body parts is known as extrapulmonary TB[1].

Despite being known for so many years and even after the availability of new and advanced diagnostic and treatment modalities the TB ranks second in terms of deaths due to infectious diseases around the world with millions of people getting a tubercular infection annually[4,6]. The chances of developing TB depend on a number of factors first the risk of being infected and second the risk of developing the active form of $\mathrm{TB}$ [5]. The former depends on the TB prevalence in the community, whereas the latter is determined by many genetic and environmental factors [5,7-9]. The situation due to TB is so grave that according to an estimate, one-third of the population in the world has a tubercular infection; nonetheless, the observed cases represent the tip of the iceberg[10,11]. It is believed that the incidence of tuberculosis has reduced from 216 per 100,000 per year in 1990 to 176 per 100,000 per year in the year 2012 in India, with about four million deaths/year due to TB[12]. Thus making India a high burden country of TB cases in the world, accounting for approximately one-fifth of the global incidence[13,14].
Also, TB makes $3.75 \%$ of India's disease burden and is one of the dominant causes of death in the 15-45 year age group[12].

To control the TB the Government of India is running the Revised National Tuberculosis Control Program under the umbrella of National Health Mission[15]. The Directly observed treatment-short course (DOTS), is an internationally recognized strategy of the RNTCP for delivering the basics of TB case-finding and cure[4]. It is not simply a clinical approach to patients, but rather a management strategy for public health systems, including political commitment, case detection through quality-assured bacteriology, short-course chemotherapy, ensuring patient adherence to treatment, adequate drug supply, and sound reporting and recording systems[16]. In the national capital New Delhi, the DOTS Program under the Revised National Tuberculosis Control Program (RNTCP) has 25 Chest Clinics spread over entire Delhi.

The Chest Clinic Moti Nagar (CCMN), a District Tuberculosis Centre (DTC) or popularly known as the Chest Clinic as it is known in Delhi DOTS Program, is the main center for all TB control activities in the district (West Delhi)[4]. As mentioned earlier in the RNTCP, the main role of the DTC has shifted from clinical to managerial functions[4]. The DTC is headed by the District TB Officer (DTO) who is a Medical Officer and is appointed by the Union Public Service Commission[17]. The DTO has the overall authority for the management of RNTCP at the district level as per the already defined RNTCP program guidelines[17]. The CCMN is located in west Delhi and it is one of the largest TB centers, which covers a population of more 
than 1.3 million. It has 24 DOT centers and 13 Designated Microscopy Centers (DMC's), under its supervision. Out of the 13 DMC's, the 12 are DMC cum DOT centers and one is purely a DMC. Similarly, out of 24 DOT centers, 11 are purely DOT centers and rests are having the facility to check the sputum. A DOT provider or TB health visitor (TBHV) is posted at each of the DOT centers and a Lab Technician (LT) is posted at each of the DMC's. Besides, the CCMN is also running the DOTS-Plus program under the RNTCP for the drug-resistant TB cases (DR-TB). The CCMN is the primary nodal point where the patient can get registered in the RNTCP's DOTS and DOTS-Plus Programs and thus there is a huge burden of the TB patients at the CCMN[4].

The WHO with its 'STOP TB' strategy has given the vision to banish TB as a public health problem from the face of this earth by 2050[4,18]. Therefore, we hereby present the detailed data related to the trends of TB in the western part of New Delhi. In this article, the author highlights the recent trends in the last six years of TB in the urban population of Western Delhi. This data will serve as an important tool to formulate new or modify the existing guidelines to control the spread of the disease, especially in an urban population.

\section{Materials and Methods}

The present study is a retrospective descriptive study and was conducted at the Chest Clinic Moti Nagar (CCMN), which is the largest center running the RNTCP in west Delhi. We analyzed the data for the last six years, i.e. from the year 2010 to 2015 . The data were collected from the quarterly reports for all these years and was tabulated. The trends in the various types of TB cases were studied and are discussed in details. The study included all the cases detected at the CCMN and who were started on the RNTCP's DOTS and DOTS-Plus strategies. Besides, the present study also gives insights into the drug-resistant $\mathrm{TB}$ cases, including the Multi-Drug Resistant (MDR) and Extensively Drug Resistant (XDR) TB at the CCMN.

\section{Results}

The current study depicts that there is an increment in the entire Category I-New Sputum Positive (NSP), New Sputum Negative (NSN), and New Extra Pulmonary (NEP) cases (Table 1). The steady rise is alarming as a number of control measures are underway to control TB. Besides, there is a steady rise in various category-II TB cases (Table 2). The major contributor to these could well be the poor nutrition and improper category-I treatment. Also, the trends in the total number of TB suspects examined and out of these the total number of sputum positive cases diagnosed (Table 3). The data show a steady increment in both the TB suspects examined and the total number of sputum positive cases diagnosed. The trends of Multi-Drug Resistant (MDR) TB detected and all such cases put on treatment is also mentioned in this study (Table 4). There is a lot of improvement in the cases put on treatment over the past six years. Table 5 shows the trends of Extensively Drug Resistant (XDR) TB detected and put on treatment. This data shows that although the total cases detected are equal to those put on treatment, but there is a steady increase in the total number of such XDR cases detected from a highly populated part of national capital of India.

Table 1: Trends of Category I-New Sputum Positive (NSP), New Sputum Negative (NSN), New Extra Pulmonary (NEP) cases

\begin{tabular}{|c|c|c|c|c|c|c|}
\hline $\begin{array}{c}\text { Types of } \\
\text { cases }\end{array}$ & \multicolumn{7}{|c|}{ Year } \\
\hline Category I & $2010(\%)$ & 2011 & 2012 & 2013 & 2014 & 2015 \\
\hline NSP & $454(34.3 \%)$ & $492(36.5 \%)$ & $479(34.7 \%)$ & $622(28.5 \%)$ & $778(27.1 \%)$ & $868(29.0 \%)$ \\
\hline NSN & $244(18.4 \%)$ & $264(19.6 \%)$ & $252(18.2 \%)$ & $487(22.3 \%)$ & $649(22.6 \%)$ & $699(23.3 \%)$ \\
\hline NEP & $624(47.2 \%)$ & $590(43.8 \%)$ & $647(46.9 \%)$ & $1071(49.1 \%)$ & $1437(50.1 \%)$ & $1425(47.6 \%)$ \\
\hline Total & $1322(100 \%)$ & $1346(100 \%)$ & $1378(100 \%)$ & $2180(100 \%)$ & $2864(100 \%)$ & $2992(100 \%)$ \\
\hline
\end{tabular}

Table 2: Trends of Category II-Recurrence, Loss to follow-up (LTFU), Failure, and Others

\begin{tabular}{|l|c|c|c|c|c|c|}
\hline Type of cases & \multicolumn{7}{|c|}{ Year } \\
\hline Category II & 2010 & 2011 & 2012 & 2013 & 2014 & 2015 \\
\hline Recurrence & $160(46 \%)$ & $211(45 \%)$ & $161(38 \%)$ & $22(5 \%)$ & $254(33 \%)$ & $297(35 \%)$ \\
\hline LTFU & $55(16 \%)$ & $50(10 \%)$ & $41(9 \%)$ & $53(13 \%)$ & $82(10 \%)$ & $80(9 \%)$ \\
\hline Failure & $14(4 \%)$ & $15(3 \%)$ & $16(3 \%)$ & $53(13 \%)$ & $20(2 \%)$ & $19(2 \%)$ \\
\hline Others & $113(33 \%)$ & $190(40 \%)$ & $195(47 \%)$ & $256(66 \%)$ & $402(55 \%)$ & $445(52 \%)$ \\
\hline Total & $342(100 \%)$ & $466(100 \%)$ & $413(100 \%)$ & $384(100 \%)$ & $758(100 \%)$ & $841(100 \%)$ \\
\hline
\end{tabular}


Table 3: Trends of TB suspect examinations done and the total smear-positive cases diagnosed

\begin{tabular}{|c|c|c|}
\hline Year & $\begin{array}{c}\text { TB suspect } \\
\text { examined }\end{array}$ & $\begin{array}{c}\text { Sputum-positive } \\
\text { case diagnosed }\end{array}$ \\
\hline 2010 & $8328(100 \%)$ & $1111(13.3 \%)$ \\
\hline 2011 & $8760(100 \%)$ & $1195(13.6 \%)$ \\
\hline 2012 & $7557(100 \%)$ & $1000(13.2 \%)$ \\
\hline 2013 & $7964(100 \%)$ & $1074(13.4 \%)$ \\
\hline 2014 & $10092(100 \%)$ & $1204(11.9 \%)$ \\
\hline 2015 & $10598(100 \%)$ & $1404(13.2 \%)$ \\
\hline
\end{tabular}

Table 4: Trends of Multi-Drug Resistant (MDR) TB detected and put on treatment

\begin{tabular}{|c|c|c|}
\hline Year & Detected MDR & Put on treatment \\
\hline 2010 & $23(100 \%)$ & $10(43.4 \%)$ \\
\hline 2011 & $34(100 \%)$ & $24(70.5 \%)$ \\
\hline 2012 & $81(100 \%)$ & $59(72.8 \%)$ \\
\hline 2013 & $60(100 \%)$ & $60(100 \%)$ \\
\hline 2014 & $96(100 \%)$ & $96(100 \%)$ \\
\hline 2015 & $95(100 \%)$ & $95(100 \%)$ \\
\hline
\end{tabular}

Table 5: Trends of Extensively Drug Resistant (XDR) TB detected and put on treatment

\begin{tabular}{|c|c|c|}
\hline Year & Detected XDR & Put on treatment \\
\hline 2010 & $2(100 \%)$ & $2(100 \%)$ \\
\hline 2011 & $3(100 \%)$ & $3(100 \%)$ \\
\hline 2012 & $4(100 \%)$ & $4(100 \%)$ \\
\hline 2013 & $8(100 \%)$ & $8(100 \%)$ \\
\hline 2014 & $2(100 \%)$ & $2(100 \%)$ \\
\hline 2015 & $9(100 \%)$ & $9(100 \%)$ \\
\hline
\end{tabular}

\section{Discussion}

Table 1 shows that there is a steady increase in New Sputum Positive (NSP), New Sputum Negative (NSN), and New Extra Pulmonary (NEP) cases in the last six years. The increase in different types of TB cases is alarming as the RNTCP is in full swing and still the results are showing a steady rise. The rise in the number of cases could be attributed to a number of factors like the new and improved diagnostic facilities, increasing awareness about TB in the population; role of Accredited Social Health Activist's (ASHA's) and NGO's to encourage the patients to take treatment for TB; advice from a cured patient in the community who encourage others to resort to DOTS after detailed clinical examination at the CCMN; advertisements about the disease in the print and media by the Government of India; audio and video commercials; regular community and district level meetings held at the various DOT centers and also at the schools, fire station, police station, metro station, etc[4]. It has been observed that the role of awareness campaigns is an integral part of the TB control[4]. Studies conducted in Serbia showed that most of the general public was not having satisfactory knowledge about TB and the same is also true for the Indian population[5,19]. The majority of the population is not aware of the basic presentations of the disease like a cough with or without expectoration, fever, loss of appetite, weight loss, etc[4]. A number of misconceptions about TB still prevail in the society [19]. In a huge country like India, it is imperative to involve every segment of the community for effective prevention and control of $\mathrm{TB}[4,12,20]$. The NEP cases have also shown a steady rise and the cases involving various parts of the body other than the lungs are included in this criterion. The higher number of NEP cases could well be due to prompt diagnosis at the government and private hospitals and then referral to the CCMN for the further management on DOTS from the different parts of Delhi.

The data in Table 2 show the trends in the previously treated cases in the last six years. The recurrence is defined as a TB patient who was declared cured or treatment completed by a physician and who reports back to the health facility and is now found to be sputum smear-positive[17]. The data show that there is an increase in the recurrence and this could well be attributed to the poor nutrition of the patients. The available data at the CCMN shows that most of the cases falling under recurrence category belong to poor socioeconomic sections of the society. Most of the cases were migrants from various other states who come to New Delhi in search of jobs. This population is mostly financially weak and live in congested areas where proper ventilation, sunlight and nutritious food are lacking. Also, higher incidences are seen in communities residing in the slums falling under the CCMN where the living conditions are very poor. 
These areas also have a prevalence of social malpractices like smoking, alcoholism and drug addiction over and above the poor and substandard living conditions. It is well documented in the literature that social malpractices like smoking and drug addiction can result in greater chances of recurrence in a known TB case[5,7,17,21]. The practice of open defecation in the western part of national capital can also be noticed in these areas.

The Loss to follow-up (LTFU) case is a TB patient, who has received treatment for TB for a month or more from any source and returns for treatment after having defaulted i.e., not taken anti-TB drugs consecutively for one month or more and found to be smear-positive[17]. The high rate of LTFU could well be due to the fact that most patients are from other states and they come to New Delhi in search of jobs, and even after regular counseling they leave New Delhi, thereby becoming a defaulter or lost to follow-up. This has been well detailed in a number of papers [22-24]. Some of the patients are the only earning members and thus they leave New Delhi for their native places due to financial constraints. Also, the most important cause that has led to a high number of LTFU is the fact that most of them were farmers and they go to their native places at the time of harvest of their crops[22-24]. Studies have reported that the side effects of drugs could well be the reason for $10 \%-50 \%$ of defaulters[22,23,25,26]. The role of side effects due to Anti-tubercular drugs (ATT) and unscrupulous practices related to superstitions prevalent in the villages also result in a higher rate of LTFU's. Besides, some of the patients are not comfortable with the alternate day directly observed treatment in the intensive phase wherein the patient has to go to the DOT center to take the medication in front of the DOT provider and thus after initial one-two months they leave the treatment when they start feeling better[17,22,25]. It has also been noticed at the CCMN and also from various parts of the country that patients who have a history of being a defaulter or who have been treated previously outside the RNTCP system, are more likely to default $[22,23,25,27]$. Some patients also resort to private practitioners and thus become LTFU from the program. The previous studies reported that about half of people with chest symptoms make the first approach to a government facility, but the preference for private sector health care has been well described[22]. A number of factors affect the attraction of the public towards the private setups some of the most important ones are proximity and a perception of better quality of care, underscored by dissatisfaction with public sector service timings, staff availability, crowds and waiting times, quality and attitude, etc.[22,28-30]. The inclination to private practitioners is more common in women than men for an initial consultation for a cough [31]. The reason could well be attributed to the stigma of TB, which makes them more reluctant to undergo sputum examination[26]. The
Indian public is also concerned too much about the marriage of their daughters and often the parents may conceal the fact that their daughter has TB[32]. Besides, the role of self-medication can also not be neglected as a potential cause of loss to follow-up cases[22]. At the CCMN the default rate control is given prime importance and for this, the role of community meeting targeting all types of TB patients is very important. The TBHV/DOT providers are well trained to counsel patients for treatment adherence and completion. As a result, the LTFU's are encouraged to take adequate treatment and thus the results are showing a gradual rise.

Any TB patient who is smear-positive at five months or more after initiation of the treatment and not put on MDR-TB treatment is defined as a failure[17]. The failure rate at the CCMN has reduced since the year 2013. The regular counseling at the CCMN by the DTO, Medical officer-TB (MO-TB), TBHV/DOT Providers and the Senior Treatment Supervisors (STS) played an important role in the control of failures. The prompt attention given to the patients facing some of the most common problems like vomiting, nausea, fever, headache, loss of appetite, etc. due to drugs has been remarkable in the reduction of the number of failures[17]. The regular encouragement by the staff for timely drug intake, sputum examination and treatment adherence is a very important factor in the control of the failures.

The rise in the number of cases in the Category-II Others, is alarming and require efforts to find the cause behind such cases. The major part of such cases is the extrapulmonary lymphadenitis and the tubercular Pott's spine[17]. The present paper does not give the details of the extrapulmonary cases of TB affecting various parts of the body, but efforts are on to provide such detailed report in near future. The misconceptions among the public about TB results in many a time delayed diagnosis of such cases[17]. However, once diagnosed the patients are given proper information and are encouraged to take complete treatment under the RNTCP.

The Table 3 shows the trends of TB suspect examinations done and the total smear-positive cases diagnosed at the CCMN. As per the RNTCP guidelines, the sputum examination is the most important part of the program. A cough is one of the most important and common symptoms of pulmonary TB $[5,9,33]$. As such undetected pulmonary TB patient, whose cough can be explained by other co-morbidities, may be a potent source of tuberculosis infection, especially for the close contacts [34]. A TB suspect is defined as an individual having a cough of two weeks or more or contacts of smear-positive TB patients having a cough of any duration or suspected/confirmed extra-pulmonary TB having a cough of any duration or HIV positive patient having a cough of any duration any TB symptom[17]. A TB suspect is having higher chances of having or 
developing TB[17]. As per the RNTCP guidelines, the TB suspects include the close contacts of a known sputum positive case, pediatric cases, PLHIV's and other immune-compromised patients[17]. The active case finding by sputum examination of the TB suspects is an integral part of the RNTCP and is going on in full swing at the CCMN as shown in Table 3. The suspects are counseled by the DOT providers/TBHV's and are encouraged for the sputum examination. The role of LT's and STLS's is also commendable. As they play a very important role in guiding the TB suspects to give a good sputum sample. The health education on symptoms of TB to the masses may greatly contribute to the prevention of TB spread within the community[5,35]. And thus the role of public and private agencies (including the NGO's like HIFA2015) involved in the dissemination of healthcare information to the general public is extremely important[36-38].

The Table 4 highlights the MDR-TB cases diagnosed and put on treatment. MDR-TB has been defined as a TB where the bacilli are resistant to isoniazid $(\mathrm{H})$ and rifampicin $(\mathrm{R})$, with or without resistance to other drugs[17,22]. The above data shows the extensive efforts of the CCMN staff to start prompt treatment of the patients detected with the MDR-TB. The present data till the first quarter of 2016 shows the presence of 149 MDR-TB cases taking treatment from various centers under the aegis of the CCMN. The higher number of MDR-TB cases, in an urban population is alarming and demands attention.

The MDR-TB develops due to spontaneous mutations in the genes of the TB bacilli[3]. However, the MDR-TB is basically a man-made problem and is a result of irregular consumption and frequent interruption in the consumption of ATT[3,17]. Also, Mishra et al. 2013, suggested that nine out of ten prescriptions for TB in India are incorrect, resulting in the wrong categorization ultimately predisposing those patients and the general population to MDR-TB in the future[36]. The same has been reported from other studies as well[22,39-41]. In the year 2013, the WHO estimated the prevalence MDR-TB amongst new cases to be around $3.5 \%$ and among re-treatment cases at $20.5 \%[3]$.

The CCMN is equipped with the services of a trained DR-TB Counselor since last one and half year. The presence of DR-TB counselor is through State Programme Officer under the project Axshya at the CCMN is an important factor in the treatment adherence and is also a major factor in prompt treatment of any side-effects associated with the DRTB drugs, as the DR-TB counselor works as a link between the patient and the doctors at the CCMN[42]. Besides, the role of DR-TB Supervisor is also very important. The DRTB Supervisor is responsible for timely registration, follow-up, and counseling of the DRTB cases. DR-TB Supervisor also visits the patient's home every 15 days and encourages them for treatment adherence. Any DR-TB case who misses the daily drug regimen under DOTS-Plus is counseled first by the TBHV/DOT Provider along with DR-TB counselor then by the STS, followed by the MO-TB and, if all the efforts are unsuccessful then the DTO visits the patient's residence in order to encourage such patients' for treatment adherence[43].

The XDR-TB is a subset of MDR-TB where the bacilli, in addition to being resistant to $\mathrm{R}$ and $\mathrm{H}$, are also resistant to fluoroquinolones and any one of the second-line injectable drugs (namely Kanamycin, Capreomycin or Amikacin)[17]. The number of XDRTB cases at the CCMN has shown a steady rise in the last six years as shown in Table 5. At present, till the fourth quarter of the year 2015, there are nine patients of XDR-TB on treatment at the CCMN. The most of these nine cases are Category-IV failures. The cure rate in the DR-TB cases, in general, is poor but at the CCMN it is well above $70 \%$ and the major part of the remaining $30 \%$ are those patients who die during the course of the treatment. There is a very small segment of transferred out and LTFU cases as well.

Besides, periodic supervisory visits as per the guidelines to the DOT centers and DMC's by the STS's, STLS's, MO-TB and DTO are a routine practice and is done to ensure proper functioning of the RNTCP's DOTS and DOTS-Plus strategies[17]. The dispersal of healthcare information to the masses is an essential component to achieve the Millennium Development Goals and to achieve the health for all, especially in a country where the annual government budget for health is meager and a majority of the population earns less than one US dollar per day[4447].

\section{TB Notifications}

TB has been a notifiable disease since $7^{\text {th }}$ May 2012 and all those patients who are taking ATT whether privately or from the government set up has to be notified[48]. The Government of India started the NIKSHAY portal so that the electronic records of all the TB cases, both public and private can be maintained[48,49]. The NIKSHAY entries are done regularly at the CCMN. The role of private practitioners and private hospitals are very important in the TB notification through the NIKSHAY portal[48,49]. So far, about 1115 cases have been notified from CCMN who are taking private ATT. In a country like India it is a remarkable achievement, as in the absence of strict laws the information about private patients on ATT is difficult to obtain and is affected by a number of factors pertaining to fear of losing the patients by private doctors, issues related to finances, issues associated with a lack of willingness to notify the cases, lack of manpower at the private setup, etc. In this regard the role of STS's is commendable. The STS's regularly visit the Tuberculosis Units and has compiled the detailed line list of the private practitioners and thus 
these practitioners are encouraged to provide details of their TB cases which can ultimately be notified.

\section{Conclusion}

$\mathrm{TB}$ is a public health problem and the higher number of cases even in the presence of a welldesigned national control program proves that the situation at the ground level needs improvements. The RNTCP has effectively and efficiently solved the problem of TB, but in order to completely eradicate the deadly disease, certain concrete steps are to be taken and implemented at the grassroots level. The total number of cases reported, are only a tip of the iceberg and there is a large segment of the population with the latent TB. New policy guidelines involving all the stakeholders involved in the TB control along with the population at risk should be made to achieve the aim of eradicating the disease by 2050 . The authors believe that similar studies should be reported from the other chest clinics from various other districts of New Delhi and also from various parts of India as this will provide valuable information which can be utilized for new policy making or for modifying the existing policies for the eradication of TB.

Competing interests: The authors declare no competing interest.

\section{Acknowledgements (if any): None}

\section{References}

1. Yadav S, Rawal G. Tubercular nodular episcleritis- A case report. J Clin Diagn Res 2015;9(8):ND01-ND02.

2. CDC. Case definitions for infectious conditions under public health surveillance. MMWR Recomm Rep. 1997;46(RR-10):1-55.

3. Yadav S, Rawal G. Primary extrapulmonary multidrugresistant tuberculosis of the sternum without HIV infection. J Clin Diagn Res 2016;10(1):RD01-RD03.

4. Yadav S. A new concept in tuberculosis awareness in the low income countries. Edorium J Tuberc 2015;5:1-4.

5. Pešut DP, Gledović ZB, Grgurević AD, NagorniObradović LM, Adžić TN. Tuberculosis Incidence in Elderly in Serbia: Key Trends in Socioeconomic Transition. Croat Med J 2008;49(6):807-12.

6. Grange JM, Greenwood D, Slack R, Peuthere JF. Medical Microbiology 15th ed. UK: ELBS Churchill Livingstone; 1998. p. 215.

7. Rieder HL. Epidemiologic basis of tuberculosis control. Paris: International Union against Tuberculosis and Lung Disease; 1999. Available from URL:-

http://www.theunion.org/what-wedo/publications/english/pub_epidemiologic_basis_eng.pd f. (Accessed on April 3, 2016).

8. Davies PD. Risk factors for tuberculosis. Monaldi Arch Chest Dis 2005;63(1):37-46.

9. Grujić M. Pulmonary tuberculosis [in Serbian]. Beograd: Naučna knjiga; 1967.

10. Miller B, Schieffelbein C. Tuberculosis. Bull World Health Organ 1998;76(Suppl 2):141-3.

11. WHO. Global Tuberculosis Report 2012. Geneva, Switzerland: World Health Organization; 2012b. Available from URL:- http://apps.who.int/iris/bitstream/10665/75938/1/9 789241564502_eng.pdf. (Accessed on October 3, 2016).

12. Gothankar JS. Tuberculosis awareness program and associated changes in knowledge levels of school students. Int J Prev Med 2013;4(2):153-7.

13. Central TB Division, Directorate General of Health Services. New Delhi: Ministry of Health and Family Welfare Nirman Bhawan; TB India. RNTCP Annual Report; 2011. p. 1.

14. WHO Report 2011. Geneva: World Health Organization; Global tuberculosis control. 2011. Available from URL:http://apps.who.int/iris/bitstream/10665/44728/1/9789241 564380_eng. pdf . (Accessed on October 3, 2016).

15. NHM Components. Available from URL:http://nrhm.gov.in/. (Accessed on April 3, 2016).

16. Geneva: WHO; 2006. World Health Organization. THE GLOBAL PLAN TO STOP TB 2006-2015: PART I Strategic directions. Available from URL: http://www.searo. who.int/LinkFiles/TB_Day_Kit_The_Global_Plan_to_St op_TB_2006-2015.pdf. (Accessed on October 3, 2016).

17. Revised National Tuberculosis Control Programme (RNTCP). Training module for medical practitioners. Available from URL:http://tbcindia.nic.in/showfile.php?lid=2908. (Accessed on October 3, 2016).

18. World Health Organization. Global Tuberculosis Report. Geneva: WHO; 2009. Available from URL:https://books.google.co.in/books?hl=en\&lr=\&id=0byXrY pnFBoC\&oi=fnd\&pg

$=$ PR5 \&dq=World+Health+Organization.+Global+Tuberc ulosis+Report.+Geneva:+WHO\%3B+2009.\&ots=GTfJlv 9_1B\&sig=WicJxgQKU8dFxothVf7Cwf0e76M\#v=onepa ge\&q=World $\% 20$ Health $\% 20$ Organization. $\% 20$ Global $\% 2$ 0Tuberculosis\%20Report.\%20Geneva\%3A\%20WHO\%3 B\%202009.\&f=false. (Accessed on October 3, 2016).

19. Vukovic D, Nagorni-Obradovic L, Bjegovic V. Knowledge and misconceptions of tuberculosis in the general population in Serbia. Eur J Clin Microbiol Infect Dis 2008;27:761-7.

20. Challu VK, Kumar P, Rao VS. Involvement of youth for TB advocacy-An innovative experiment. NTI Bull 2005;41:71-5.

21. World Health Organization. Tobacco Control Country Profiles. 2nd ed. Atlanta: World Health Organization; 2003. Available from URL:http://www.who.int/tobacco/global_data/country_profiles /en/. (Accessed on October 3, 2016).

22. Mistry N, Tolani M, Osrin D. Drug-resistant tuberculosis in Mumbai, India: An agenda for operations research. Oper Res Health Care 2012;1(2-3):45-53.

23. Jaiswal A, Singh V, Ogden JA, Porter JD, Sharma PP, Sarin R. Adherence to tuberculosis treatment: lessons from the urban setting of Delhi, India. Trop Med Int Health 2003;8(7):625-33.

24. Bagchi S, Ambe G, Sathiakumar N. Determinants of poor adherence to anti-tuberculosis treatment in Mumbai, India. Int J Prev Med 2010;1(4):223-32.

25. Jaggarajamma K, Sudha G, Chandrasekaran V, Nirupa C, Thomas A, Santha T. Reasons for non-compliance among patients treated under Revised National Tuberculosis Control Programme (RNTCP), Tiruvallur district, south India. Indian J Tuberc 2007;54(3):130-35.

26. Dandona R, Dandona L, Mishra A, Dhingra S, Venkatagopalakrishna K, Chauhan LS. Utilization of and barriers to public sector tuberculosis services in India. Natl Med J India 2004;17(6):292-99. 
27. Jha UM, Satyanarayana S, Dewan PK, Chadha S, Wares F, Sahu S. Risk factors for treatment default among retreatment tuberculosis patients in India, 2006. PLoS One 2010;5(1):e8873.

28. Kelkar-Khambete A, Kielmann K, Pawar S, Porter J, Inamdar V, Datye A. India's revised national tuberculosis control programme: looking beyond detection and cure. Int J Tuberc Lung Dis 2008;12(1):87-92.

29. Charles N, Thomas B, Watson B, Raja Sakthivel M, Chandrasekeran V, Wares F. Care seeking behavior of chest symptomatics: a community based study done in South India after the implementation of the RNTCP. PLoS One 2010;5(9):e12379.

30. Satyanarayana S, Nair SA, Chadha SS, Shivashankar R, Sharma G, Yadav S. From where are tuberculosis patients accessing treatment in India? Results from a crosssectional community based survey of 30 districts. PLOS One 2011;6(9):e24160.

31. Balasubramanian R, Garg R, Santha T, Gopi PG, Subramani R, Chandrasekaran V. Gender disparities in tuberculosis: report from a rural DOTS programme in South India. Int J Tuberc Lung Dis 2004;8(3):323-32.

32. Uplekar M, Pathania V, Raviglione M. Private practitioners and public health: weak links in tuberculosis control. Lancet 2001;358(9285):912-16.

33. Wejse C, Gustafson P, Nielsen J, Gomes VF, Aaby P, Andersen PL, et al. TB score: Signs and symptoms from tuberculosis patients in a low-resource setting have predictive value and may be used to assess clinical course. Scand J Infect Dis 2008;40(2):111-20.

34. Veen J. Microepidemics of tuberculosis: the stone-in-thepond principle. Tuber Lung Dis 1992;73:73-6.

35. World Health Organization. Management of tuberculosis. Training for health facility staff. Module D: inform patients about TB. Geneva: World Health Organization; 2003. Available from URL:http://www.who.int/hiv/Training_TB_Coordinators.pdf. (Accessed on April 3, 2016).

36. Yadav S, Rawal G. Healthcare information for all-Is it achievable? Int J Sci Res Rev 2015;4(1):101-5.

37. Yadav S, Rawal G. The HIFA and the HealthPhone: Laying the foundation for combating malnutrition in India. Int J Health Sci Res 2015;5(7):368-71.

38. Yadav S, Rawal G. Self-medication practice in low income countries. Int J Pharmaceut Chem Anal 2015;2(3):139-142.
39. Uplekar MW, Shepard DS. Treatment of tuberculosis by private general practitioners in India. Tuberc 1991;72(4):284-90.

40. Anandhi CL, Nagaraj VK, Kumar R. Knowledge and practice pattern of non-allopathic indigenous medical practitioners regarding tuberculosis in a rural area of India. Int J Tuberc Lung Dis 2002;6(6):553-5.

41. Prasad R, Nautiyal RG, Mukherji PK, Jain A, Singh K, Ahuja RC. Treatment of new pulmonary tuberculosis patients: what do allopathic doctors do in India? Int $J$ Tuberc Lung Dis 2002;6(10):895-902.

42. Project Axshya. Available from URL:http://www.axshya-theunion.org/. (Accessed on April 3, 2016).

43. Revised National Tuberculosis Control Programme. Guidelines on Programmatic Management of Drug Resistant TB (PMDT) in India. Available from URL:http://tbcindia.gov.in/WriteReadData/1892s/8320929355 Guidelines\%20for\%20PMDT\%20in\%20India\%20\%20May\%202012.pdf. (Accessed on April 3, 2016).

44. Yadav S, Rawal G. Role of integrating community health workers in achieving healthcare information for all. Int $J$ Sci Res Rev 2015;4(1):106-10.

45. Yadav S, Rawal G. Counterfeit drugs: Problem of developing and developed countries. Int J Pharmceut Chem Anal 2015;2(1):46-50.

46. Yadav S, Rawal G. Primary extrapulmonary extensively drug resistant tuberculosis of the hip in an immunocompetent female-A case report. J Clin Diagn Res 2017;11(1):LD01-LD03.

47. Yadav S, Rawal G, Baxi M. Plagiarism-A serious scientific misconduct. Int J Health Sci Res. 2016;6(2):364-6.

48. TB India 2016. Revised National TB Control Programme. Annual Status report. Available from URL:http://www.tbcindia.nic.in/showfile.php?lid=3180. (Accessed on April 3, 2016).

49. Jitendra R. 'NIKSHAY' - harnessing Information technology for delivery of enhanced TB care. NTI Bulletin 2012;48(1\&4):1-4.

How to cite this article: Yadav S, Rawal G. The recent trends in tuberculosis in the urban population of Western Delhi- A detailed report from a large center. Indian J Immunol Respir Med. 2018;3(4):196-202. 